(C) 2021, The Authors. Published by Elsevier Inc. and Fass Inc. on behalf of the American Dairy Science Association ${ }^{\circledR}$. This is an open access article under the CC BY-NC-ND license (http://creativecommons.org/licenses/by-nc-nd/4.0/).

\title{
Proteomic analysis of differentially expressed whey proteins in Saanen goat milk from different provinces in China using a data-independent acquisition technique
}

\author{
Zixuan Zhao, ${ }^{1}$ Ning Liu, ${ }^{1}$ Cuina Wang,,${ }^{1,2 *} \odot$ Jianjun Cheng,,${ }^{1 *}$ and Mingruo Guo ${ }^{3}$ \\ ${ }^{1}$ Key Laboratory of Dairy Science, Northeast Agricultural University, Harbin, Heilongjiang, 150030, China \\ ${ }^{2}$ Department of Food Science, Jilin University, Changchun, 130062, China \\ ${ }^{3}$ Department of Nutrition and Food Sciences, College of Agriculture and Life Sciences, University of Vermont, Burlington 05405
}

\begin{abstract}
Whey proteins of Saanen goat milk samples from 3 provinces in China (Guangdong, GD; Inner Mongolia, IM; Shaanxi, SX) were characterized and compared using data-independent acquisition quantitative proteomics technique. A total of 550 proteins were quantified in all 3 samples. There were 44, 44, and 33 differentially expressed proteins (DEP) for GD versus IM, GD versus SX, and IM versus SX, respectively. Gene ontology annotation analysis showed that the largest number of DEP for the 3 comparisons were as follows: for biological processes: response to progesterone, glyceraldehyde-3-phosphate metabolic process, and negative regulation of megakaryocyte differentiation; for molecular functions: antioxidant activity, binding, and peroxiredoxin activity; and for cellular components: the same category of extracellular regions for the 3 comparisons, respectively. Pathways for the DEP of 3 comparisons were (1) disease; (2) synthesis and metabolism; and (3) synthesis, degradation, and metabolism. Protein-protein interaction network analysis showed that DEP for GD versus SX had the most interactions. Key words: Saanen goat milk, whey protein, dataindependent acquisition
\end{abstract}

\section{INTRODUCTION}

Goat milk is attracting increasing attention because of its low allergenicity and easy digestibility compared with cow milk (Izquierdo-González et al., 2019). The high nutritional value of goat milk is related to its protein (Costa et al., 2014), which can be classified into caseins, whey proteins, and milk fat globule membrane proteins. Whey protein accounts for about $20 \%$

\footnotetext{
Received November 6, 2020.

Accepted May 17, 2021.

*Corresponding authors: wangcuina@jlu.edu.cn and jjcheng@neau edu.cn
}

of the total protein (Rahmatalla et al., 2020) and is a high-quality protein source. Goat milk whey proteins are easily absorbed and utilized by the human body (Brodziak et al., 2014). The whey proteins in goat milk comprise various proteins, the number and composition of which depend on many factors, including goat breed and region (Costa et al., 2014). Cunsolo et al. (2015) identified 452 whey proteins in Camosciata goat milk using a proteomics technique. Sun et al. (2019) characterized 283 whey proteins in Guanzhong goat milk using EASY-nano liquid chromatography combined with orbitrap-tandem mass spectrometry. Sun et al. (2020) determined that there were 314 and 524 whey proteins in Xinong Saanen goat colostrum and mature milk, respectively. Diet also greatly influences goat milk composition (e.g., adding Leucaena to the TMR may reduce the urea content in Saanen goat milk; Leketa et al., 2019).

Proteomics is a basic technique for systematic identification and characterization of protein structure, function, activity, quantity, and molecular interactions (Gerber et al., 2003). Proteomics analysis mainly relies on liquid chromatography-MS/MS. The previous strategy developed for MS data acquisition is datadependent acquisition (DDA; Fernández-Costa et al., 2020). However, tandem MS (MS/MS) spectra collected using DDA technology rarely sample the part with the strongest signal of the peptide elution profile (Egertson et al., 2013). As many as 15 to $20 \%$ of MS/MS spectra sampled from complex mixtures are chimeric. Low-intensity ions cannot be quantified in DDA technology because they are always ignored (Bourassa et al., 2015). To solve these problems, a high-throughput data-independent acquisition (DIA) mode has emerged in recent years (Lin et al., 2018). In DIA mode, all samples can be scanned and low-abundance protein can be detected (Lin et al., 2018). Data-independent acquisition can provide high accuracy, dynamic range, and reproducibility of selected reaction monitoring (Gillet et al., 2012; Liu et al., 2014). 
Data-independent acquisition is a popular and promising method for protein identification and quantification. In this study, we characterized and compared whey protein profiles of Saanen goat milk samples collected from Guangdong, Inner Mongolia, and Shaanxi in China using DIA quantitative proteomics technology. The data were compared for bioinformatics analysis of whole identified proteins and differentially expressed proteins (DEP) between goat milks from 2 regions at a time. The whole quantified whey proteins were analyzed using Gene Ontology (GO) annotation and Kyoto Encyclopedia of Genes and Genomes (KEGG) pathway analyses. We identified DEP between each pair of regions for GO and KEGG enrichment and conducted a protein-protein interaction (PPI) analysis.

\section{MATERIALS AND METHODS}

\section{Materials and Sampling}

Mature Saanen goat milk was sampled (30 samples each) from 3 different regions of China, including Guangdong (GD; Meizhou, 115.897567E, 24.572625N), Shaanxi (SX; Xi'an, 108.946166E, 34.349382N), and Inner Mongolia (IM; Hohhot, 111.755426E, 40.848119N). Mature milk was collected from 2- to 3-yr-old Saanen goats in third to sixth parity. Samples were collected in 50-mL centrifuge tubes in the morning from September 15 to 21, 2019. Samples were transported to the laboratory by cold chain and stored at $-80^{\circ} \mathrm{C}$ until analysis. Protease inhibitors, urea, trypsin, acetone, bicinchoninic acid protein assay kit, dithiothreitol, acetonitrile, iodoacetamide, and ammonium bicarbonate were provided by Sigma-Aldrich Corp. Feed for Saanen goats in GD was composed of $60 \%$ mountain top grass, $20 \%$ mountain foot grass, and 20\% rich and nourishing concentrated feed. Feed for Saanen goats in IM was a mixture of green oil wheat, silage, corn stover, soybean hulls, and rich and nourishing concentrated feed. The Saanen goat feed in SX was a blend of okara, silage, cauliflower leaves, sweet elephant grass, and rich and nourishing concentrated feed. Nourishing concentrated feed was composed of corn, soybean meal, distillers dried grains, cotton meal, corn husks, and so on, and provided by the local farm.

\section{Preparation of Whey Protein}

Goat milk samples (containing protease inhibitors) were centrifuged at $860 \times g$ at $4^{\circ} \mathrm{C}$ for $60 \mathrm{~min}$. Two layers were obtained, including a fat layer and a skim milk layer (from top to bottom). The skim milk layer was adjusted to $\mathrm{pH} 4.6$ with $10 \%$ acetic acid and then centrifuged at $9,600 \times g$ at $4^{\circ} \mathrm{C}$ for $15 \mathrm{~min}$. The supernatant $(10 \mathrm{~mL})$ was taken, and 4-fold volume of prechilled acetone was added. The mixture was left at $-20^{\circ} \mathrm{C}$ overnight to precipitate the whey proteins. Whey protein was then obtained by washing the precipitate 6 to 9 times with cool acetone and then dried. The whey protein was quantified using a bicinchoninic acid kit.

\section{Digestion of Whey Proteins}

To $100 \mu \mathrm{g}$ of protein sample, urea $(8 M)$ was added to a volume of $200 \mu \mathrm{L}$, and dithiothreitol was added to a final concentration of $10 \mathrm{~m} M$. The mixture was incubated at $37^{\circ} \mathrm{C}$ for $2.5 \mathrm{~h}$, and then iodoacetamide was added to a final concentration of $50 \mathrm{~m} M$. The mixture was incubated at room temperature for 40 min in the dark and then transferred to a $10-\mathrm{K}$ tube (MRCPRT010, Merck). After the mixture was centrifuged at $12,000 \times g$ at room temperature for $30 \mathrm{~min}$, the filtrate was discarded. Urea $(8 M, 400 \mu \mathrm{L})$ was added into the mixture and centrifuged again at 12,000 $\times g$ at room temperature for $30 \mathrm{~min}$ and the filtrate was discarded. This step was repeated twice. Then, 400 $\mu \mathrm{L}$ of ammonium bicarbonate solution $(50 \mathrm{mM})$ was added to the UF tube and centrifuged at $12,000 \times g$ at room temperature for $30 \mathrm{~min}$, and the filtrate was discarded. This step was repeated 3 times, and the temperature was set at room temperature for the first time and $4^{\circ} \mathrm{C}$ for $30 \mathrm{~min}$ for the next 2 times. Ammonium bicarbonate solution $(50 \mathrm{mM}, 200 \mu \mathrm{L})$ was added to the UF tube, and then trypsin was added to the UF tube at a mass ratio of sample to enzyme at 50:1. The mixture was incubated at $37^{\circ} \mathrm{C}$ for $16 \mathrm{~h}$ with a shaker and centrifuged at $12,000 \times g$ at $4^{\circ} \mathrm{C}$ for $30 \mathrm{~min}$. The peptides were obtained by freeze-drying the collected filtrate.

\section{High pH Reversed-Phase Chromatography Separation}

Methanol (1 mL) was used to activate the chromatographic column. Acetonitrile $(80 \%)$ and liquid ammonia ( $\mathrm{pH} \mathrm{10)}$ at a volume of $1 \mathrm{~mL}$ were used to clean the chromatographic column for 3 times. Liquid ammonia $(\mathrm{pH} 10,1 \mathrm{~mL})$ was used to equilibrate the chromatographic column. Freeze-dried peptides were dissolved in $200 \mu \mathrm{L}$ of liquid ammonia ( $\mathrm{pH} 10)$ and then loaded into the column. The peptides were separated into 3 fractions by eluting liquid ammonia ( $\mathrm{pH} 10)$ with $6,9,12$, $15,18,21,25,30,35$, and $50 \%$ acetonitrile in sequence. The separated fractions were lyophilized for use. 


\section{Liquid Chromatography-MS/MS Experiments}

Data of all the peptides were obtained from Q ESXctive HF and Easy nanoLC 1000 (Thermo Scientific) for DIA analysis. Each peptide sample $(3 \mu \mathrm{g})$ was loaded onto the chromatography column and separated with an aqueous solution with $0.1 \%$ (vol/vol) formic acid in buffer $\mathrm{A}$ and acetonitrile with $0.1 \%$ (vol/vol) formic acid in buffer $\mathrm{B}$ for $180 \mathrm{~min}$ at a flow rate of 600 $\mathrm{nL} / \mathrm{min}$. Then, it was connected to an oven at $60^{\circ} \mathrm{C}$. The DDA analysis was performed with precursor MS spectral analysis at 400 to $1,200 \mathrm{~m} / z$ and analyzed at a resolution of $120 \mathrm{k}$ at $400 \mathrm{~m} / \mathrm{z}$, and then the first 20 ions were selected with an isolation window of $2 \mathrm{Da}$. For dynamic exclusion time and maximum injection time, MS1 and MS2 of the tandem MS were at 20 and $50 \mathrm{~ms}$, respectively. For DIA analysis, the $m / z$ range was 400 to 1,200 , and the resolution was 60,000 , followed by 29 variable DIA scans with a resolution of 30,000 .

\section{DDA Data Search and DIA Data Analysis}

All DDA raw data were uploaded to the Sequest HT node integrated in the Proteome Discoverer software (version 2.1, Thermo Fisher Scientific), and the Biognosys iRT peptide sequence was added through the Mouse Uniprot fasta database $(83,625$ entries, downloaded on March 18, 2019; https://www.uniprot.org). The miss cleavage site set was 2. Carbamidomethylation of cysteine was set as static modification, and oxidation of Met and deamidation of Asn and Gln were set as dynamic modifications. The false discovery rate (FDR) of peptides and proteins was 1\%. The DDA search results were imported into Skyline (4.2.0.18305) to generate the library. Then, DIA raw data of 9 samples were imported for quantification. We used the mProphet (Reiter et al., 2011) peak scoring model (each data set and iteration were trained independently) to reintegrate all detected peaks, and q-value annotations were added to each peak. Then, MSstats (version 2.4.0, R package, https://www.r-project.org/) was used to output protein quantitative results for further bioinformatics analysis.

\section{Bioinformatics Analysis}

UniProt database (https://www.uniprot.org/) was used to obtain specific information on all proteins determined in this study. The CAZy annotations were obtained using the CAZy database (http://www.cazy .org/). We conducted GO and KEGG analysis of proteins using online David 6.8 software (http://david .abcc.ncifcrf.gov/home.jsp). The PPI analysis was per- formed using STRING online database (version 11.0, https://string-db.org/).

\section{RESULTS AND DISCUSSION}

\section{Characterization of Quantitatively Identified Proteins}

The proteomics technique has been widely used to identify and characterize whey proteins in milk from different species. Liu et al. (2020) identified 161 serum proteins in raw bovine milk using a label-free proteomic approach. Li et al. (2018) quantified 580 whey proteins of Murrah, Nili-Ravi, and Mediterranean buffaloes through tandem mass tag proteomics. Scumaci et al. (2015) identified 342 colostrum whey proteins in $15 \mathrm{Ap}$ penninic sheep (3-4 yr old). In this study, we used the DIA proteomic technique to identify the whey proteins in Saanen goat milk in 3 different provinces in China. A total of 550 whey proteins were found, and the detailed information on these quantified proteins is shown in Supplemental Table S1 (https://data.mendeley.com/ datasets/rz3yzznv6s/1, Zhao, 2021). More proteins were identified in this study compared with other studies (Anagnostopoulos et al., 2016; Sun et al., 2019, 2020), which may be due to the reversed-phase chromatography fractionation and DIA quantitative proteomics technology. According to the CAZy database, there were a total of 124 enzymes in 550 proteins. The enzymes were divided into 5 categories (i.e., auxiliary activities, carbohydrate-binding modules, carbohydrate esterases, glycoside hydrolases, and glycosyl transferases). Each category had 3, 54, 3, 28, and 36 enzymes, respectively (Figure 1A). Most of the proteins were involved in carbohydrate binding. Among the top 10 proteins with the highest abundances, 9 proteins were shared by the 3 regions, which were not listed in this study. $\beta$-Lactoglobulin and $\alpha$-LA, which are common proteins, were the top 2 in abundance in all 3 regions, and albumin was third most abundant in milk from GD and SX. The detected differences in protein abundance may be due to the different feeds of the goat and location of the 3 provinces. For example, from north to south, IM and SX span 6 latitudes, and SX and GD span 16 latitudes.

The strongest correlation was observed between samples collected from GD and SX, with a correlation coefficient of 0.91 . The correlation coefficients for samples between GD and SX and between IM and SX were 0.90. Figure 1B shows the density map of whey proteins in the 3 goat milk samples. Figure 1B suggests that protein abundances of GD and SX were closer than those of other location pairs. 

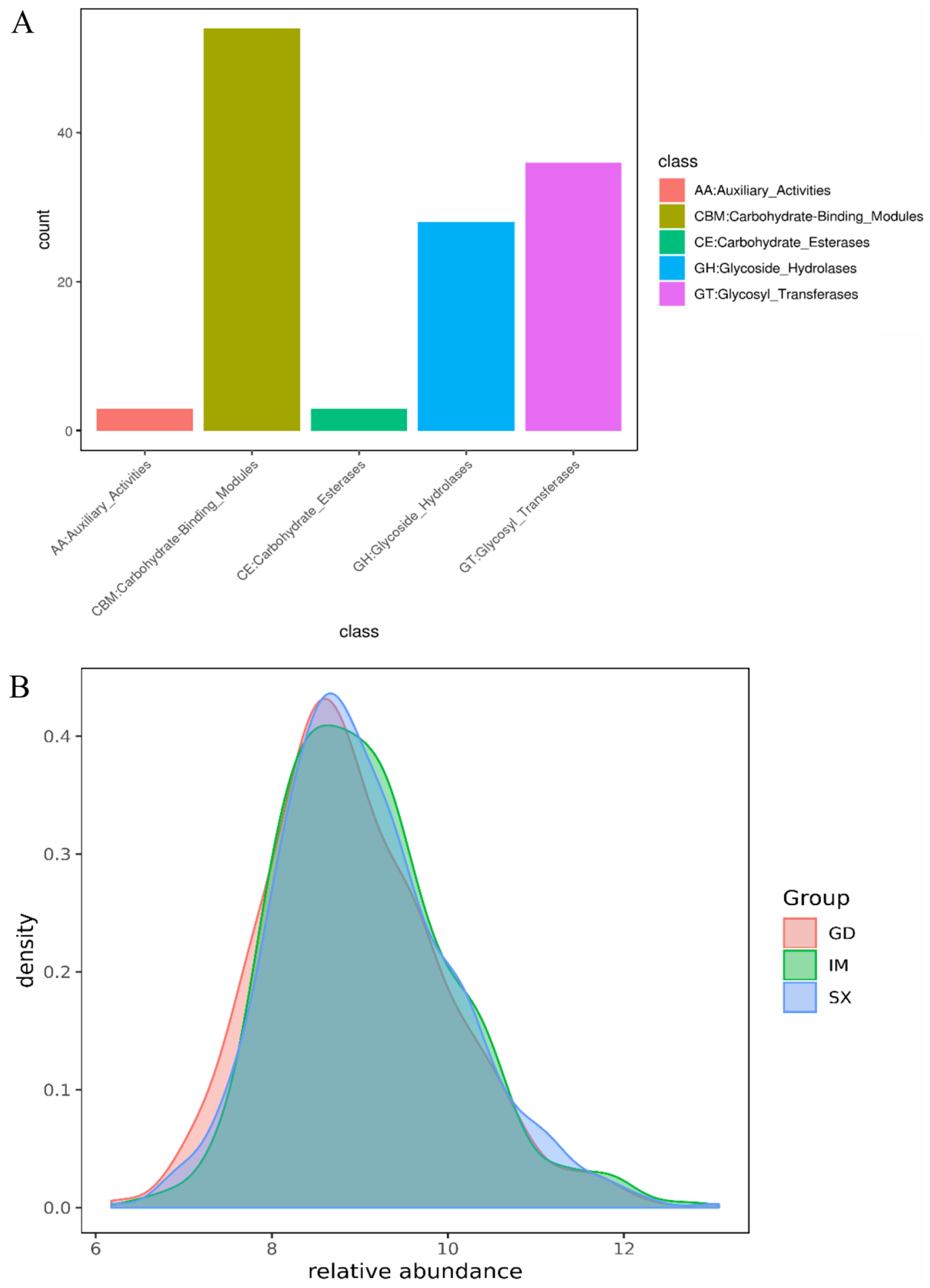

Figure 1. Enzyme classification (A) and density map (B) of the whey protein identified in goat milk collected from 3 regions in China: Guangdong (GD), Inner Mongolia (IM), and Shaanxi (SX). The x-axis represents logarithm of the relative abundance, and the y-axis represents probability density. 


\section{GO Annotation and KEGG Pathway Analysis}

The GO functional annotation is divided into 3 aspects: biological process (BP), cellular components (CC), and molecular function (MF). All identified proteins were annotated for GO function and the results are shown in Figure 2A. Regarding BP, most proteins acted on cellular processes. For CC, proteins were mainly involved in cell, cell part, and organelle part. With respect to MF, most proteins had functions of binding, followed by catalytic activity and molecular function regulator. These results were similar to those of Anagnostopoulos et al. (2016), which showed that the top $3 \mathrm{MF}$ categories for Greek goat milk were catalytic activity, nucleotide binding, and metal ion binding.

The KEGG pathway analysis is a primary analysis of biological pathways and can be divided into the following 5 branches: (1) cellular processes, (2) environmental

A

Function Classification (GO)

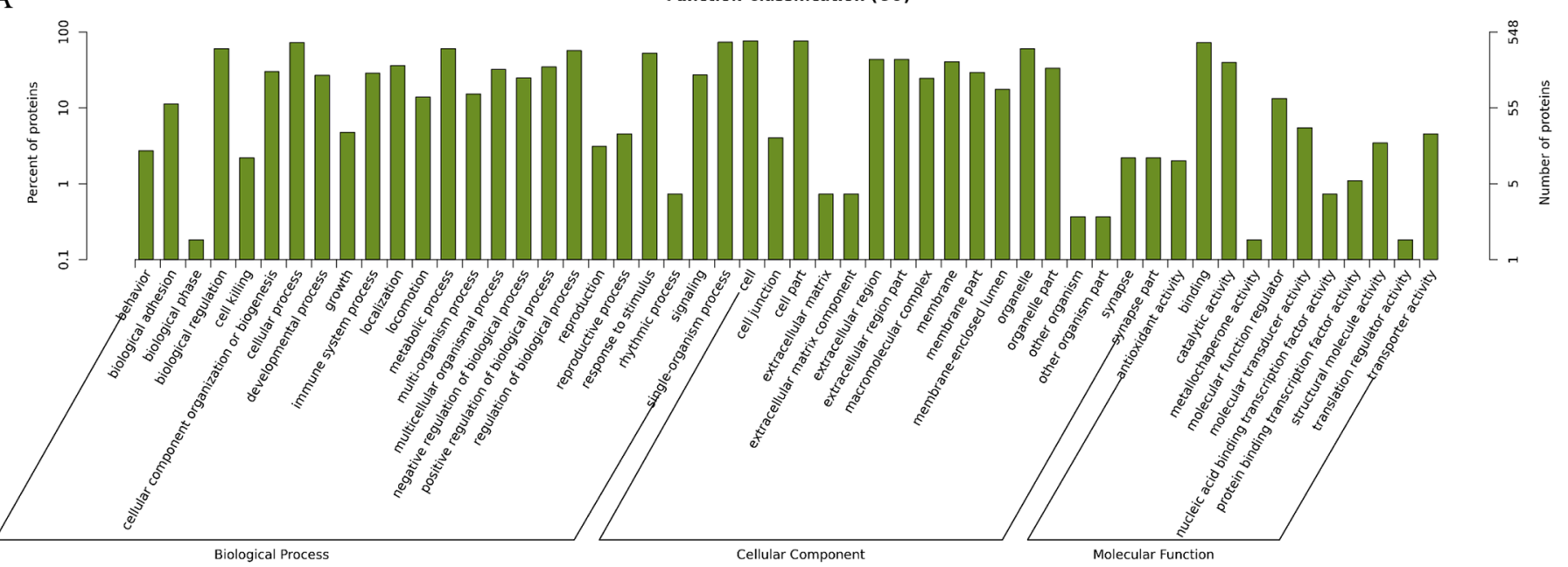

B

KEGG Classification

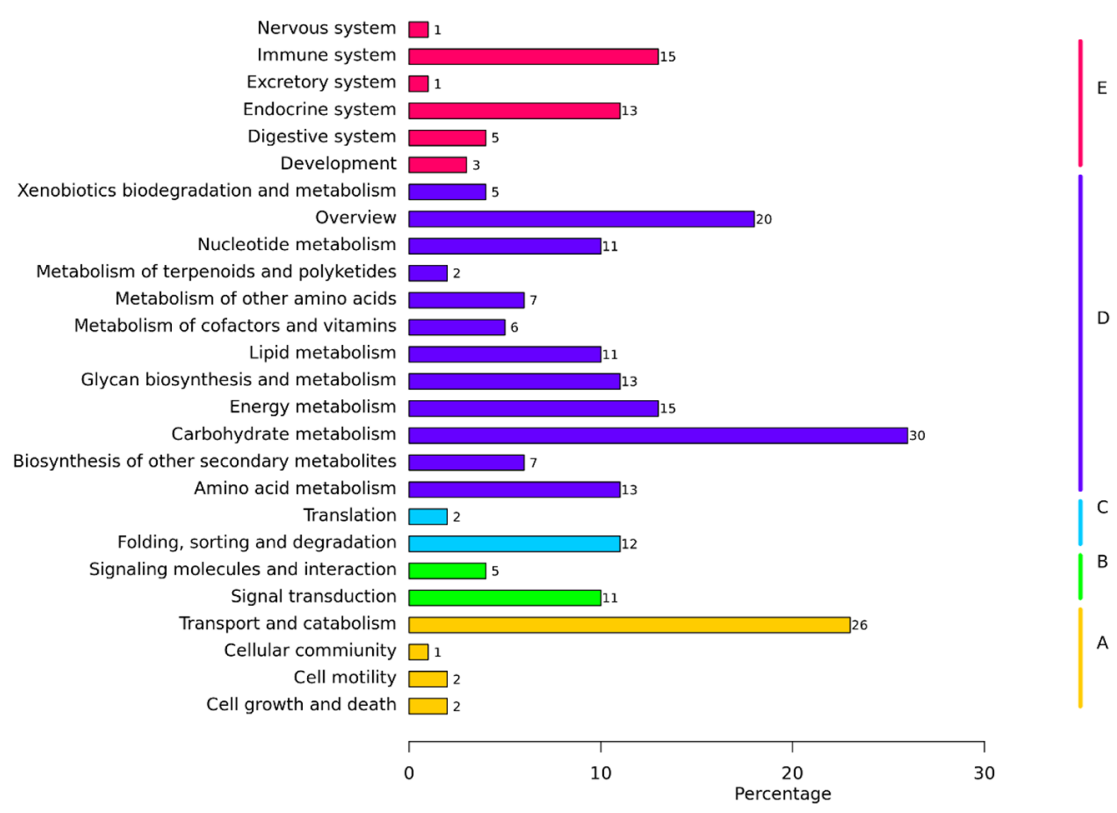

Figure 2. (A) Gene Ontology (GO) function annotation, and (B) Kyoto Encyclopedia of Genes and Genomes (KEGG) metabolic pathway map for whey proteins identified in goat milk collected from 3 regions in China. A, cellular processes; B, environmental information processing; C, genetic information processing; D, metabolism; and E, organismal systems, which respectively correspond to (1), (2), (3), (4), and (5) of the GO Annotation and KEGG Pathway Analysis in the paper. 
information processing, (3) genetic information processing, (4) metabolism, and (5) organismal systems. All identified proteins were subjected to KEGG analysis, and the results are shown in Figure 2B. All proteins were involved in a total of 26 pathways, and most involved pathways were related to carbohydrate metabolism, cell transport, and catabolism. For cellular processes, there were 4 pathways, of which 26 of the proteins were mainly involved in transport and catabolism. For the environmental information processing section, 11 of the proteins were involved in signal transduction, and 5 proteins were involved in signaling molecules and interaction. For genetic information processing, 12 of the proteins were involved in folding, sorting, and degradation. For metabolism, the relevant pathway for whey protein participation was carbohydrate metabolism (30 terms), which reflected the metabolic performance, physiological and nutritional status of organisms, and ability to adapt to the external environment (Wang et al., 2017). In organismal systems, 15 proteins participated in the immune system, and among them, 11 types of proteins were involved in regulating complement and coagulation cascades. The complement and coagulation cascades were related to cell adhesion, migration and proliferation, B cell receptor signaling pathways, and phagocytosis (Falanga et al., 2013; Kourtzelis and Rafail, 2016; Afshar-Kharghan, 2017).

\section{Characterization of DEP}

Identified whey proteins of goat milk from each pair of regions were compared, and proteins with fold changes $>2$ or $<0.5$ and FDR $<0.4$ were selected as DEP, which can be used to distinguish and classify Saanen goat milk whey proteins from the 3 regions.

A total of 44 DEP for GD versus IM, including 8 upregulated and 36 downregulated proteins, were found as shown in the volcano picture (Figure 3A). The top 3 significant DEP among upregulated proteins were the ones with the accession numbers of A0A452FMC2 $(\mathrm{FDR}=0.0006), \mathrm{A} 0 \mathrm{~A} 452 \mathrm{EJM} 6(\mathrm{FDR}=0.0049)$, and A0A452E243 $(\mathrm{FDR}=0.0252)$, which have not been characterized according to the Uniprot database. The protein with the largest difference among downregulated proteins was that with accession number A0A452EFJ3, which has also not been characterized; it is a proteaseassociated (PA) domain-containing protein.

A total of 44 DEP, 13 upregulated and 31 downregulated, were identified for GD versus SX (Figure 3B). The most significant one among the upregulated proteins was major facilitator superfamily (MFS) domain-containing protein $(\mathrm{FDR}=0.0041)$, whereas that for the downregulated proteins was galectin. Galectin constitutes a family of animal $\beta$-galactoside-binding lectins and contains few carbohydrate recognition domains (Chiariotti et al., 2002). Galectin is synthesized and stored in the cytoplasm and released or secreted by cells as a pattern recognition receptor when there is a long-term infection or tissue damage caused by infection. These infectious diseases act as immunomodulators or cytokine-like modulators in innate responses (Sato et al., 2009).

When samples from IM and SX were compared, 33 DEP (24 upregulated and 9 downregulated) were found (Figure 3C). The most significant upregulated proteins were the same as those for GD versus SX. The most significant downregulated protein has not yet been characterized in Uniprot $(\mathrm{FDR}=0)$, and the second most significant protein is peroxiredoxin-6 (updated by Uniprot; FDR $=0.0152$ ). Peroxiredoxin is a common family of nonselenium peroxidases with molecular weight ranging from 22 to $27 \mathrm{kDa}$. The main function of peroxiredoxin is to catalyze peroxide reduction and balance the hydrogen peroxide level in cells (Park et al., 2016). The peroxidase family is involved in invasion and metastasis of cancer cells, and it may be a new target for cancer radiotherapy (Zhang et al., 2009; Chen et al., 2018).

\section{Analysis of Venn Diagram for DEP}

The distribution of DEP between each comparison was studied and the results are shown in Figure 3D. The comparisons of GD versus IM and IM versus SX have 6 common DEP, 2 upregulated and 4 downregulated. There were 12 common DEP for GD versus IM and GD versus SX, of which 10 were downregulated and 2 were upregulated. The most different downregulated protein was alkaline phosphatase. Alkaline phosphatase exists in most human tissues, such as liver and kidney, blood cells, and bones (Rankin et al., 2010). Alkaline phosphatase is also present in milk (Shakeel-ur-Rehman et al., 2003), and it can be used to characterize the correct pasteurization in milk (Harding and Garry, 2005). Groups of IM versus SX, and GD versus SX have 6 common DEP, including 2 downregulated proteins and 4 upregulated proteins, of which the highly significantly upregulated protein is MFS domain-containing proteins.

The 3 compared pairs had 1 common DEP, histone $\mathrm{H} 4$, which had the highest abundance in samples collected from GD. Histones are involved in several cellular processes such as transcription, repair, and recombination (Marayati et al., 2020). A high level of histone $\mathrm{H} 4$ is one of the important risk factors leading to an increased probability of death in patients with 

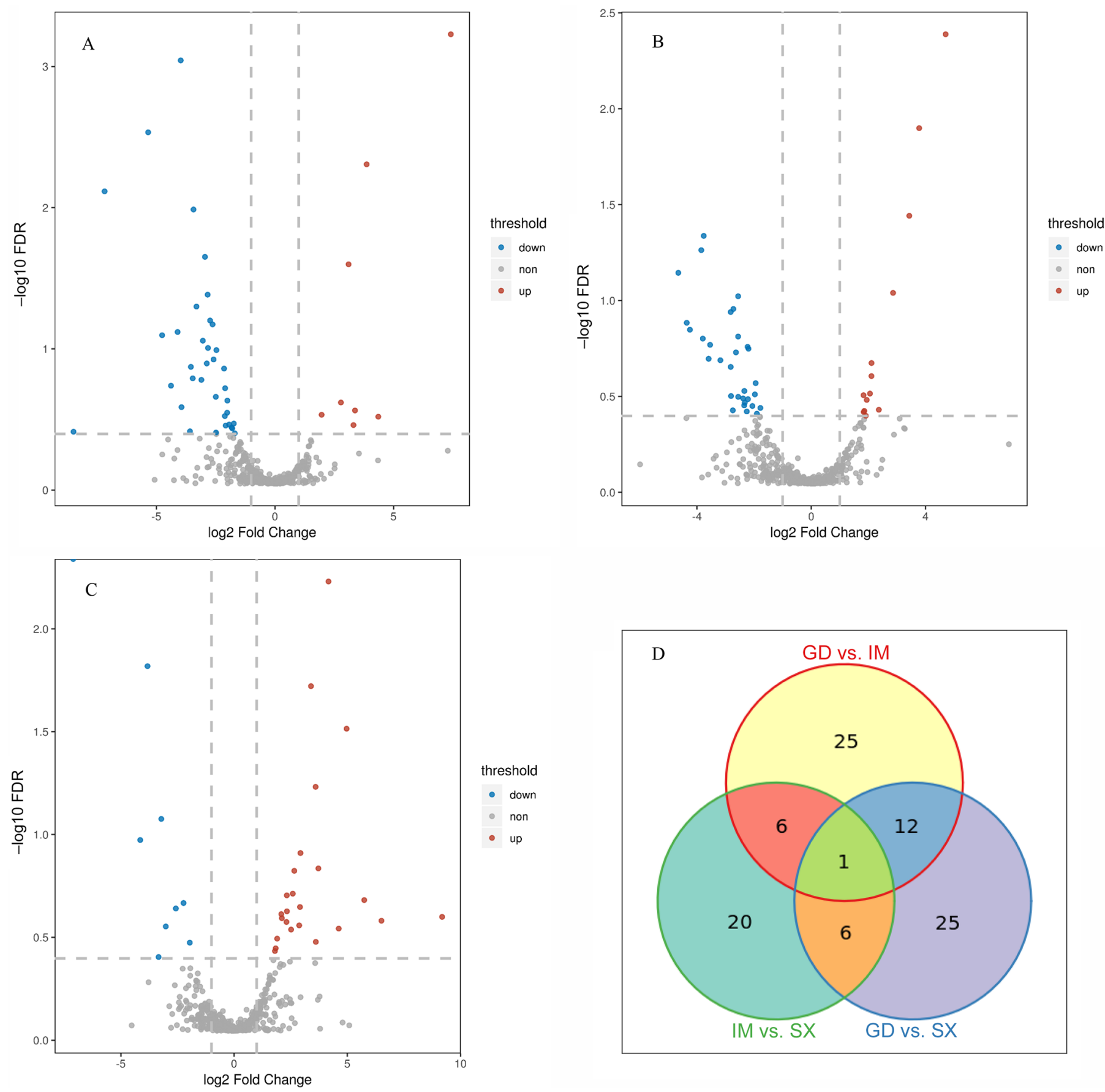

Figure 3. Volcano diagram (A, B, C) and Venn diagram (D) for differentially expressed proteins of whey proteins in goat milk for GD versus IM, GD versus SX, and IM versus SX. GD = Guangdong; IM = Inner Mongolia; SX = Shaanxi; FDR = false discovery rate.

sepsis, and it is also considered an effective biomarker for evaluating sepsis (Lu et al., 2020).

\section{GO Enrichment Analysis of DEP}

The DEP between each pair of regions underwent GO enrichment analysis, and the results are shown in
Figure 4. The 44 DEP for GD versus IM showed significant enrichment in $10 \mathrm{BP}$ terms, $19 \mathrm{CC}$ terms, and $1 \mathrm{MF}$ term $(P<0.05$; Figure $4 \mathrm{~A})$. With respect to $\mathrm{BP}$, most DEP were involved in the category of response to progesterone, followed by participation in cellular detoxification and detoxification processes. For CC, DEP acted mainly on extracellular regions. The categories 
with the largest numbers of DEP were antioxidant activity and extracellular region under MF, followed by membrane-bounded vesicle and vesicle. Goat milk with whey proteins is high in antioxidant activity and may be beneficial to consumers by reducing oxidative damage caused by free radicals (Lakram et al., 2019). Three proteins were involved in response to progesterone, all of which were downregulated. There were 23 proteins involved in the extracellular region, of which 2 were upregulated and 21 were downregulated. Four proteins were involved in antioxidant activity, of which 2 were upregulated, and 2 were downregulated.

The DEP for GD versus SX showed significant enrichment in $18 \mathrm{BP}$ terms, $11 \mathrm{CC}$ terms, and $1 \mathrm{MF}$ term $(P<0.05$; Figure $4 \mathrm{~B})$. For BP, most DEP were involved in the glyceraldehyde-3-phosphate and the glucose 6-phosphate metabolic processes. With respect to $\mathrm{CC}$, DEP in the category of extracellular regions ranked first, followed by extracellular region parts, membrane-bounded vesicles, and vesicles. The DEP mainly had the molecular function of binding. There was a total of 3 proteins involved in the glyceraldehyde-3-phosphate metabolic process, all of which were downregulated proteins. There were 23 proteins involved in the extracellular region, of which 6 were upregulated and 17 were downregulated. Twenty-four were involved in binding, with 7 upregulated and 17 downregulated.

For IM versus SX, DEP had significant enrichment in BP (10 terms), CC (16 terms), and MF (4 terms; $P$ $<0.05$; Figure $4 \mathrm{C}$ ). With respect to BP, DEP mainly acted on negative regulation of megakaryocyte differentiation. For CC, whey proteins were mainly in the extracellular region, followed by extracellular region part, extracellular exosome, and extracellular vesicle. Regarding MF, peroxiredoxin activity was the main function, and oxidoreductase activity and antioxidant activity also played important roles. Two proteins were involved in regulation of megakaryocyte differentiation, both of which were downregulated. Fifteen proteins were involved in the extracellular region, of which 10 were upregulated and 5 were downregulated. Two proteins were involved in peroxiredoxin activity, and both were downregulated.

\section{KEGG Pathway Analysis of DEP}

Forty terms were found with $P<0.05$ for the DEP of GD versus IM, and among them, amoebiasis, phagosome, and systemic lupus erythematosus were the top significant 3 terms (Figure 4D). The pathway in which most DEP participated in was metabolic pathway, including 1 upregulated and 7 downregulated proteins.
Most DEP for GD versus SX were involved in synthetic and metabolic pathways, such as biosynthesis of AA, folate biosynthesis, and the pentose phosphate pathway (Figure $4 \mathrm{E}$ ). One of the significant pathways was the renin-angiotensin system metabolic pathway (Figure 5A), which exists in all organs of the body and is closely related to regulation of blood pressure. It was reported that SARS-CoV-2 may be particularly harmful to patients with cardiovascular disease (South et al., 2020), perhaps because SARS-CoV-2 results in the imbalance of the renin-angiotensin system and can lead to a further increase in blood pressure. In this pathway, 2 DEP were detected, peptidase S1 domain-containing protein and ATPase $\mathrm{H}(+)$-transporting lysosomal accessory protein 2 , both of which were downregulated. The position of renin-angiotensin system metabolic pathway and protein function in the pathway are shown in Figure 5A (blue box represents protein position). Two DEP can regulate the biological effects of the pathway by regulating upstream and downstream proteins. For example, AGT can be directly changed to ANG2 under the action of peptidase S1 domaincontaining protein. Also, AGT can also be transformed into ANG1 by REN and then change into ANG2 under action of peptidase S1 domain-containing protein. Both pathways may cause blood pressure to increase. Simultaneously, blood pressure can be lowered via hydrolyzing ANG1 and ANG2 by ACE2. Thus, the blood pressure balance can be regulated. Additionally, REN can act on PRR [corresponding to ATPase $\mathrm{H}(+)$-abysosomal accessory protein 2] to promote protein synthesis on the cell membrane, resist apoptosis, and inhibit cell proliferation. It has been reported that ACE2 is the receptor for SARS-CoV-2 (Samavati and Uhal, 2020) and binding with SARS-CoV-2 resulted in the remarkably decreased ACE2 content in human cells. Subsequently, ANG2 expression increases relatively and blood pressure increases further. Moreover, SARS-CoV-2 has caused multiple organ damage in humans.

For DEP of IM versus SX, most proteins were involved in pathways of synthesis, degradation, and metabolism, and the results are shown in Figure $4 \mathrm{~F}$. The pathway for galactose metabolism is shown in Figure 5B. The red box represents DEP for the following pathway: $\beta$-galactosidase $(\boldsymbol{\beta}$-gal) converts lactose into $\mathrm{D}$-galactose or $\alpha$-D-galactose, thereby regulating the pathway balance. The literature shows $\beta$-gal is a common enzyme that catalyzes hydrolysis of terminal $\beta$-galactosidic linkages in glycoproteins (Tanaka et al., 1975). The literature also shows that $\beta$-gal is highly active in patients with human glioma (Wielgat et al., 2006) and also related to rheumatoid arthritis inflammation (Su et al., 2020). 
A. The Most Enriched GO Terms (GD vs. IM)

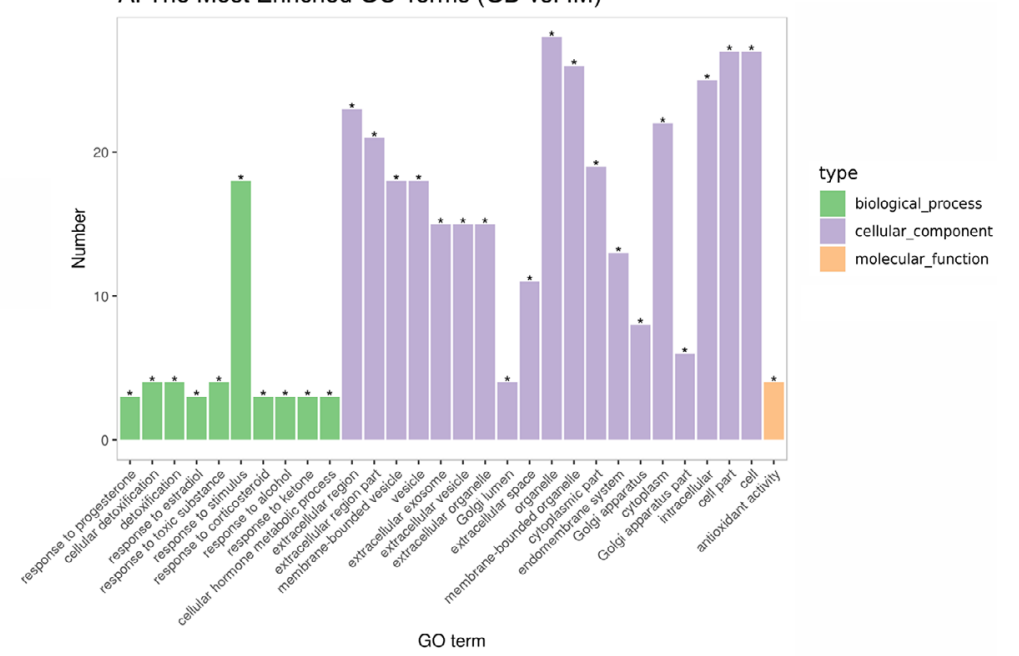

B. The Most Enriched GO Terms (GD vs. SX)

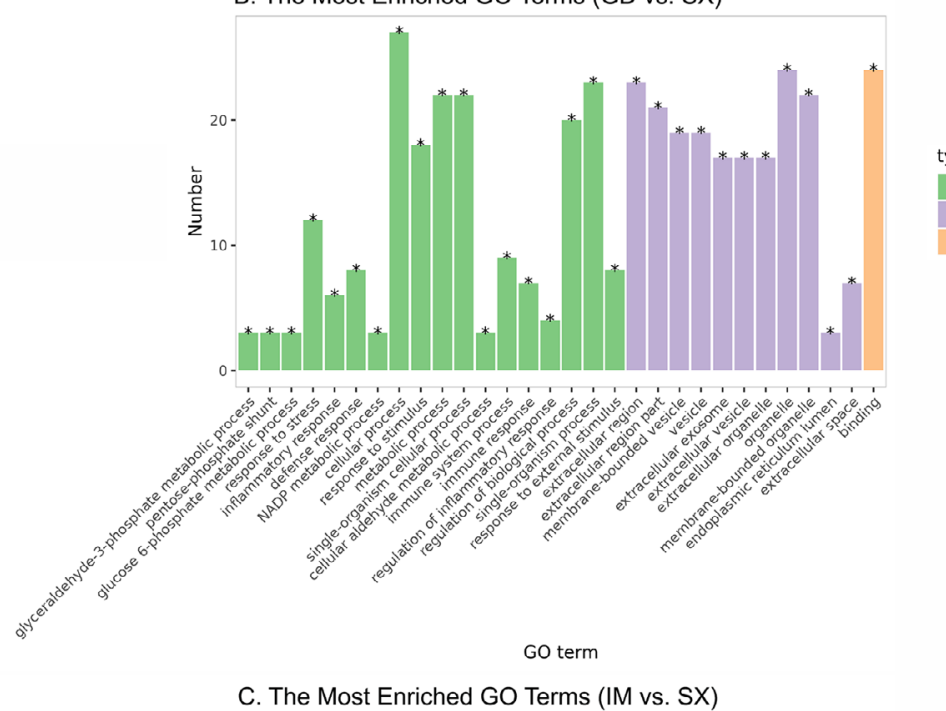

type

biological_process

cellular_component

molecular_function

C. The Most Enriched GO Terms (IM vs. SX)

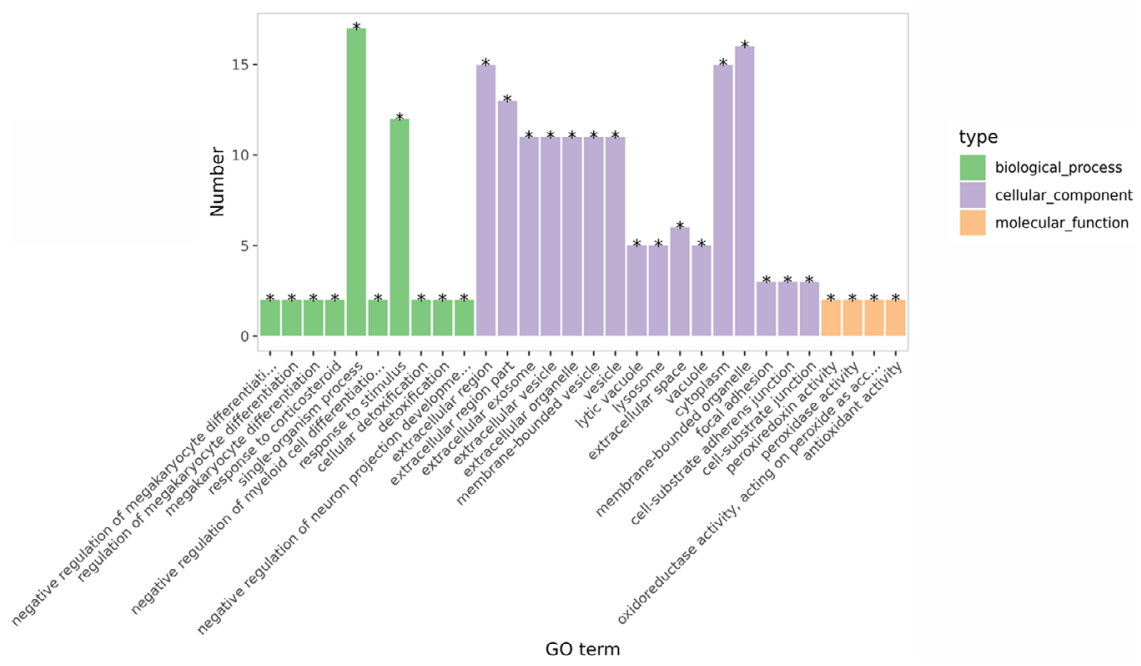

Figure 4. Histogram of Gene Ontology (GO) enrichment classification (A, B, C) and statistics of Kyoto Encyclopedia of Genes and Genomes (KEGG) pathway enrichment (D, E, F) for differentially expressed proteins of whey proteins in goat milk for GD versus IM, GD versus SX, and IM versus SX. The asterisk on each bar in the bar chart represents statistical significance. The top 20 GO enrichment results are shown in order of $P$-value from smallest to largest. GD = Guangdong; IM = Inner Mongolia; SX = Shaanxi. 

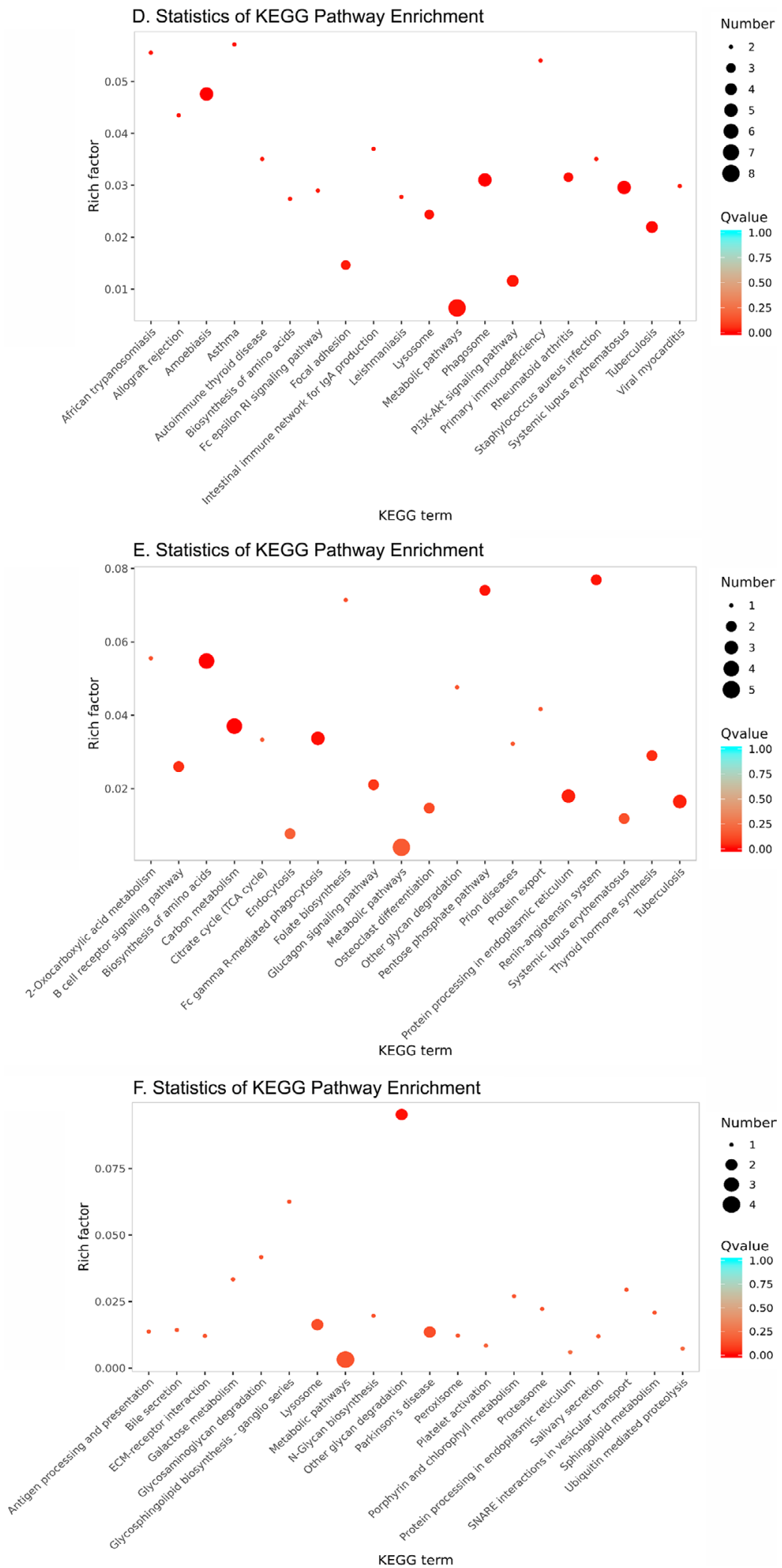

Figure 4 (Continued). Histogram of Gene Ontology (GO) enrichment classification (A, B, C) and statistics of Kyoto Encyclopedia of Genes and Genomes (KEGG) pathway enrichment (D, E, F) for differentially expressed proteins of whey proteins in goat milk for GD versus IM, GD versus SX, and IM versus SX. The asterisk on each bar in the bar chart represents statistical significance. The top 20 GO enrichment results are shown in order of $P$-value from smallest to largest. GD = Guangdong; IM = Inner Mongolia; SX = Shaanxi. 
A RENIN - ANGIOTENSIN SYSTEM

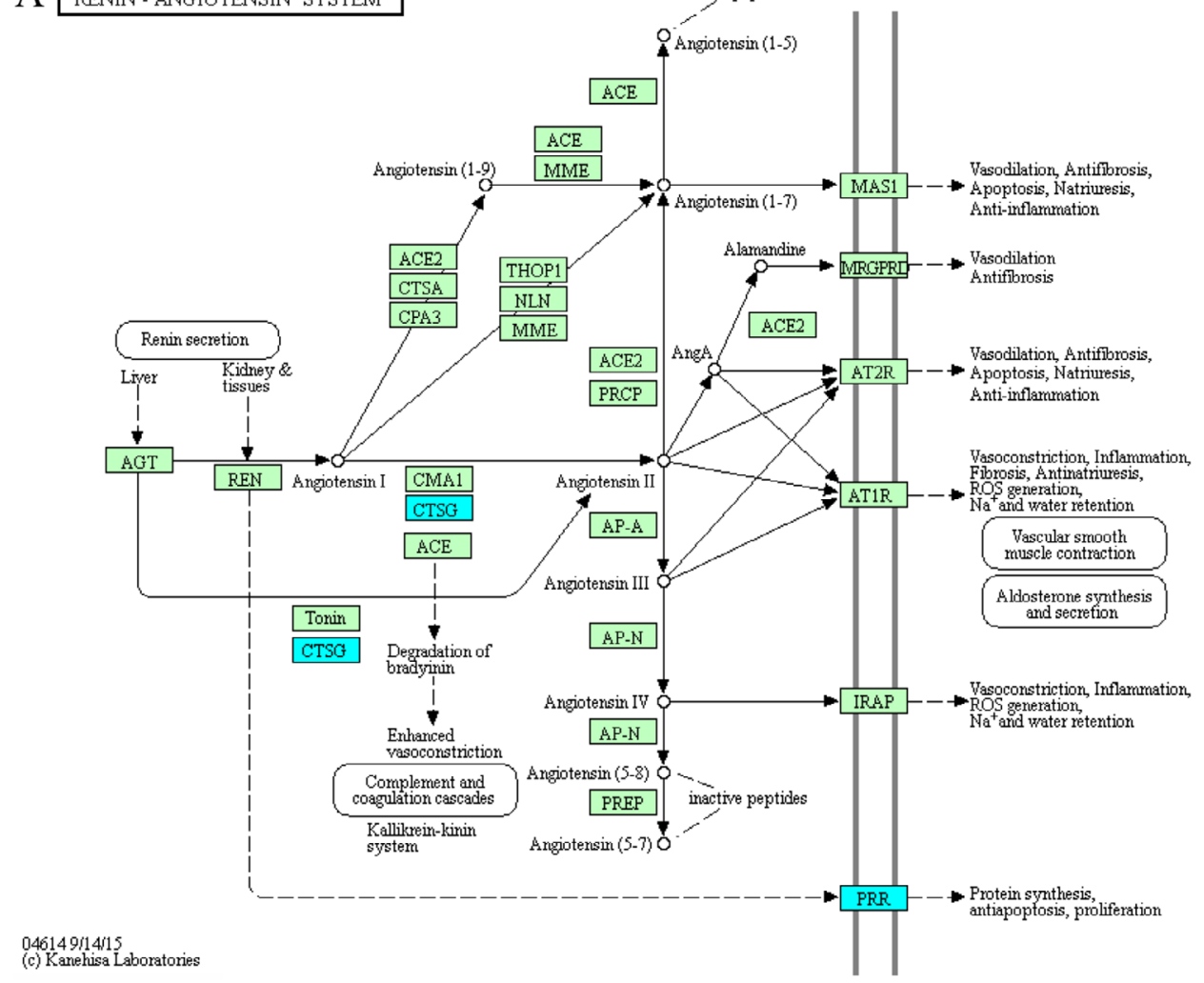

$\mathrm{B}$ GALACTOSE METABOLISM

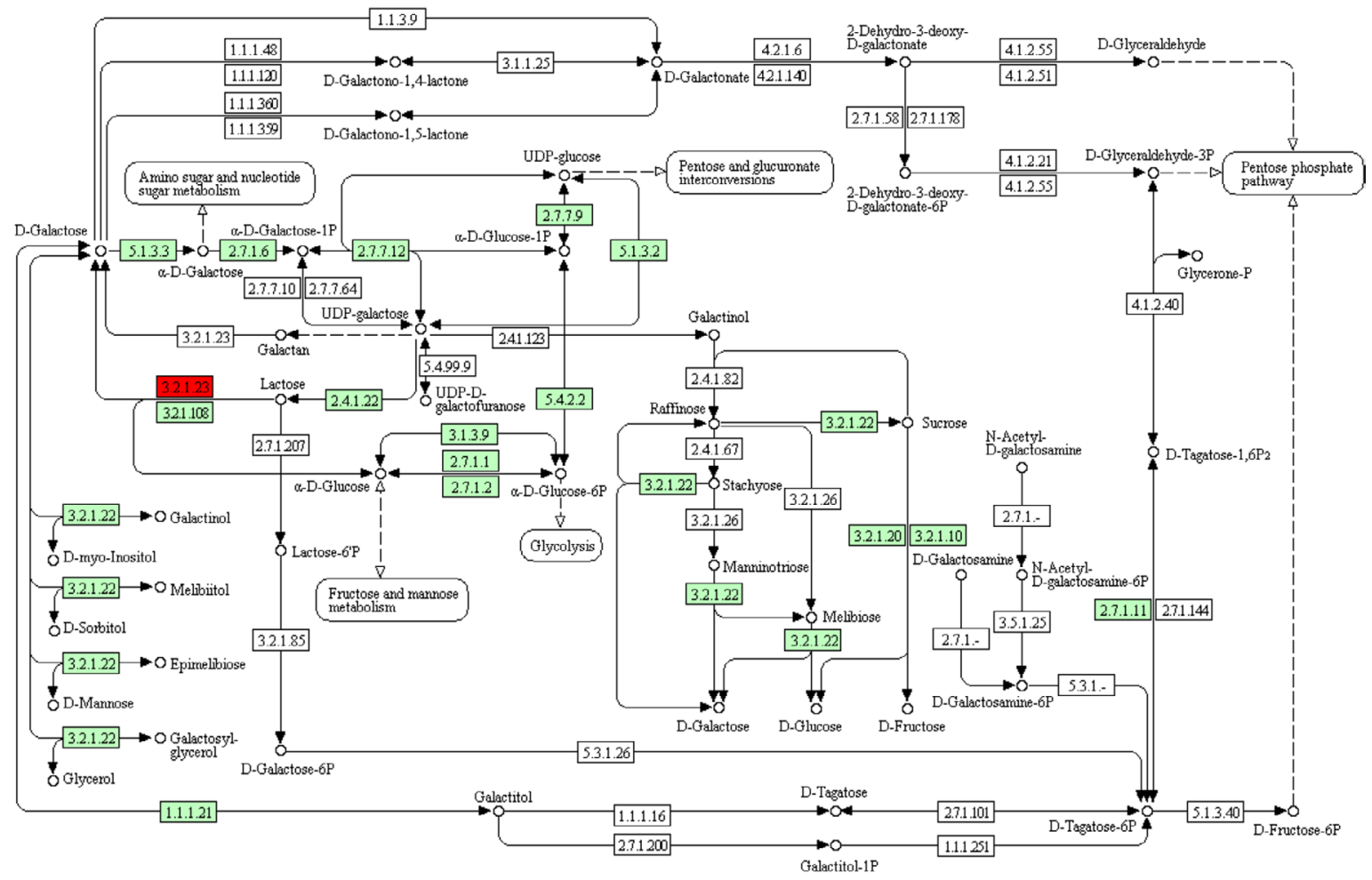

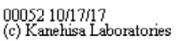

Figure 5. Kyoto Encyclopedia of Genes and Genomes (KEGG) pathway diagram for (A) renin-angiotensin system and (B) pathway diagram for galactose metabolism (Kanehisa and Goto, 2000; Kanehisa, 2019; Kanehisa et al., 2021). Used with permission of Kanehisa Laboratories. 

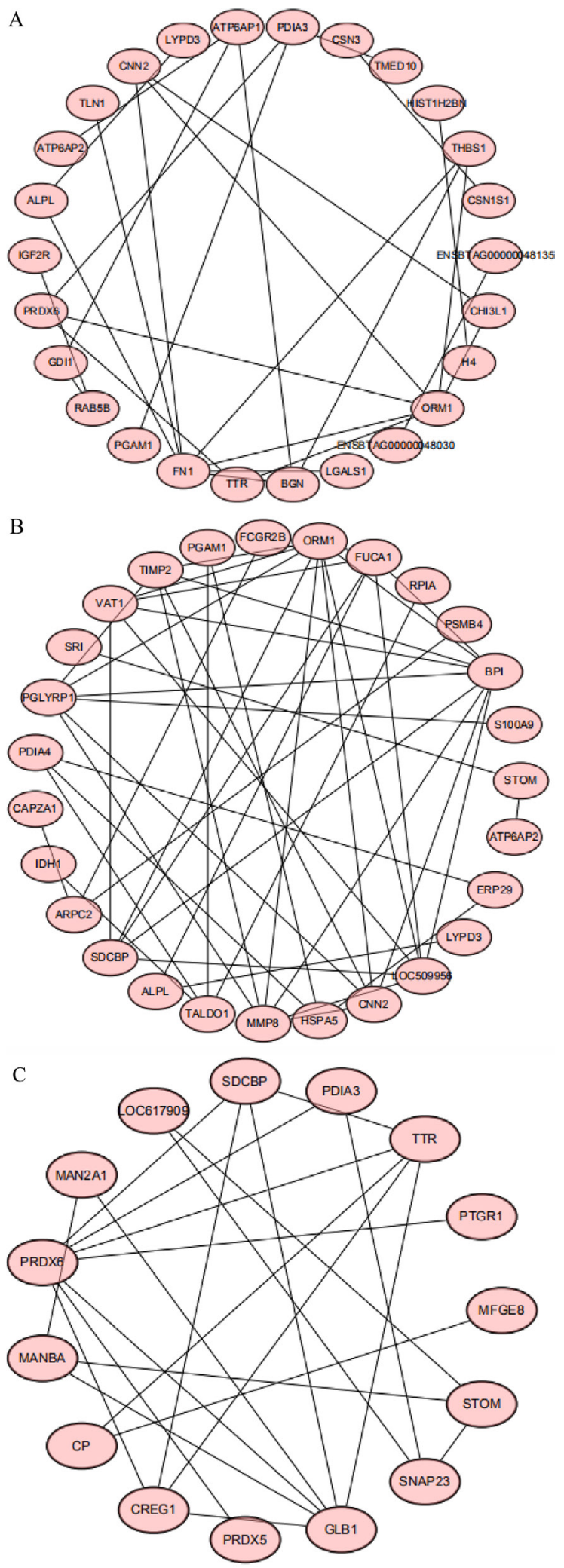

Figure 6. Protein-protein interaction network map for differentially expressed proteins of whey proteins in goat milk for (A) GD versus IM, (B) GD versus SX, and (C) IM versus SX. GD = Guangdong; IM $=$ Inner Mongolia; SX = Shaanxi.

\section{PPI Network Analysis of DEP}

Studying the interactions between proteins helps to identify core regulatory proteins. There are many PPI databases; STRING is an online search database that covers the most species and has extensive interaction information. The DEP for each paired comparison across the 3 regions were analyzed for PPI using the STRING database, the data imported into Cytoscape v3.8.2 software, and the top 10 hub genes in PPI network selected using the CytoHubba plug-in. The results are shown in Figure 6, where circled nodes represent proteins and connections between nodes represent protein-protein interactions.

The PPI network analysis for DEP of GD versus IM (Figure 6A) showed that it contained a 26 nodes and 27 edges. The top 10 hub genes were, in order, FN1, ORM1, CNN2, THBS1, PDIA3, BGN, PRDX6, $A T P 6 A P 1, R A B 5 B$, and TTR. Fibronectin 1 is a large adhesion glycoprotein in the extracellular matrix that has multiple binding domains with cell surface and extracellular ligands (Goossenset al., 2009). It has been reported to be a potential biomarker for radiation resistance in squamous cell carcinoma of head and neck (Jerhammar et al., 2010). One of the reasons for low survival rate of patients with nasopharyngeal cancer is that high concentration fibronectin 1 tumor cells are expressed, and fibronectin 1 may be an independent prognostic factor for nasopharyngeal carcinoma ( $\mathrm{Yu}$ et al., 2020).

Figure 6B shows the PPI network for DEP of GD versus SX, which contained 27 nodes and 46 edges. The top 10 hub genes were ORM1, BPI, CTSG, MMP8, FUCA1, PGLYRP1, SDCBP, CNN2, VAT1, and TIMP2. ORM was first discovered more than $100 \mathrm{yr}$ ago, and it has a variety of physiological functions, including immune regulation, drug binding, and transport (Luo et al., 2015). The protein BPI is a cationic protein with molecular weight of $55 \mathrm{kDa}$ (Theprungsirikul et al., 2020) and has strong bactericidal activity against some gram-negative organisms (Gazzano-Santoro et al., 1992). CTSG is a serine protease (Meyer-Hoffert, 2009) that has a wide range of biological activities, including regulating functions and antibacterial properties (Zamolodchikova et al., 2020). delaCadena et al. (1996) proposed that the activity of $\alpha$-L-fucosidase in tumor tissue is lower than that in healthy mucosa. Also, $\alpha-\mathrm{L}-$ fucosidase may have a certain effect on patients with a high-risk of tumor recurrence of colorectal cancer (Fernández-Rodríguez et al., 2000).

The DEP for IM versus SX had 15 interacting proteins and 23 protein interactions, as shown in Figure 6C. The top 10 hub genes were PRDX6, GLB1, TTR, SDCBP, CREG1, SNAP23, MANBA, STOM, MAN2A1, and 
$C P$. Peroxidase is a highly versatile protein that plays a vital role in regulating the level of peroxides in cells (Zeida et al., 2019). In particular, it is the center of cell redox homeostasis and signal transduction (PastorFlores et al., 2020). Also, PRDX6 is highly expressed in lungs (Sundar et al., 2010) and is the only member of $P R D X$ family that can move to damaged mitochondria (Yang et al., 2016), thus protecting nonalcoholic fatty liver disease by regulating mitochondria (Lee et al., 2019).

\section{CONCLUSIONS}

In this study, we characterized and compared Saanen goat milk samples collected from 3 provinces of China for whey proteins using a DIA quantitative proteomics technique. About 550 proteins were quantified in goat milk from each region. There were 124 enzymes out of 550 proteins, and most of the proteins were involved in carbohydrate-binding. The proteins of goat milk from GD and SX were most similar in composition. The DEP differed significantly in GO, KEGG pathways, and PPI. Theses difference may have been caused by different feeds of the goats and the location of the different provinces. Data of this study may provide useful information for use of Saanen goat milk in China, and the DEP can be used for discrimination and classification of Saanen goat milk of different geographic origins.

\section{ACKNOWLEDGMENTS}

This project was funded by a grant of the Thirteenth Five-Year Plan of the Ministry of Science and Technology of China (Beijing, China; No. 2018YFC1604304). The authors have not stated any conflicts of interest.

\section{REFERENCES}

Afshar-Kharghan, V. 2017. The role of the complement system in cancer. J. Clin. Invest. 127:780-789. https://doi.org/10.1172/ JCI90962.

Anagnostopoulos, A. K., A. I. Katsafadou, V. Pierros, E. Kontopodis, G. C. Fthenakis, G. Arsenos, S. C. Karkabounas, A. Tzora, I Skoufos, and G. T. Tsangaris. 2016. Milk of Greek sheep and goat breeds; characterization by means of proteomics. J. Proteomics 147:76-84. https://doi.org/10.1016/j.jprot.2016.04.008.

Bourassa, S., F. Fournier, B. Nehmé, I. Kelly, A. Tremblay, V. Lemelin, B. Lamarche, P. Couture, and A. Droit. 2015. Evaluation of iTRAQ and SWATH-MS for the quantification of proteins associated with insulin resistance in human duodenal biopsy samples. PLoS One 10:e0125934. https://doi.org/10.1371/journal.pone .0125934 .

Brodziak, A., J. Król, J. Barłowska, and Z. Litwińczuk. 2014. Effect of production season on protein fraction content in milk of various breeds of goats in Poland. Int. J. Dairy Technol. 67:410-419. https: //doi.org/10.1111/1471-0307.12130.

Chen, L., C. Huang, X. Yang, Q. Zhang, and F. Chen. 2018. Prognostic roles of mRNA expression of peroxiredoxins in lung cancer.
Onco. Targets Ther. 11:8381-8388. https://doi.org/10.2147/OTT S181314.

Chiariotti, L., P. Salvatore, R. Frunzio, and C. B. Bruni. 2002. Galectin genes: Regulation of expression. Glycoconj. J. 19:441-449. https://doi.org/10.1023/B:GLYC.0000014073.23096.3a.

Costa, W. K. A., E. L. Souza, E. M. Beltrão-Filho, G. K. V. Vasconcelos, T. Santi-Gadelha, C. A. de Almeida Gadelha, O. L. Franco, and M. Magnani. 2014. Comparative protein composition analysis of goat milk produced by the Alpine and Saanen breeds in northeastern Brazil and related antibacterial activities. PLoS One 9:e93361. https://doi.org/10.1371/journal.pone.0093361.

Cunsolo, V., E. Fasoli, R. Saletti, V. Muccilli, S. Gallina, P. G. Righetti, and S. Foti. 2015. Zeus, Aesculapius, Amalthea and the proteome of goat milk. J. Proteomics 128:69-82. https://doi.org/10 .1016/j.jprot.2015.07.009.

delaCadena, M., J. Fernandez, A. deCarlos, V. MartinezZorzano, E. GilMartin, and F. RodriguezBerrocal. 1996. Low levels of alphaL-fucosidase activity in colorectal cancer are due to decreased amounts of the enzymatic protein and are related with Dukes' stage. Int. J. Oncol. 9:747-754. https://doi.org/10.3892/ijo.9.4 .747 .

Egertson, J. D., A. Kuehn, G. E. Merrihew, N. W. Bateman, B. X. MacLean, Y. S. Ting, J. D. Canterbury, D. M. Marsh, M. Kellmann, V. Zabrouskov, C. C. Wu, and M. J. MacCoss. 2013. Multiplexed MS/MS for improved data-independent acquisition. Nat. Methods 10:744-746. https://doi.org/10.1038/nmeth.2528.

Falanga, A., M. Marchetti, and A. Vignoli. 2013. Coagulation and cancer: Biological and clinical aspects. J. Thromb. Haemost. 11:223233. https://doi.org/10.1111/jth.12075.

Fernández-Costa, C., S. Martínez-Bartolomé, D. B. McClatchy, A. J. Saviola, N.-K. Yu, and J. R. Yates III. 2020. Impact of the identification strategy on the reproducibility of the DDA and DIA results. J. Proteome Res. 19:3153-3161. https://doi.org/10.1021/ acs.jproteome.0c00153.

Fernández-Rodríguez, J., D. Ayude, M. Cadena, V. Martínez-Zorzano, A. de Carlos, A. Caride-Castro, G. de Castro, and F. J. RodríguezBerrocal. 2000. Alpha-L-fucosidase enzyme in the prediction of colorectal cancer patients at high risk of tumor recurrence. Cancer Detect. Prev. 24:143-149.

Gazzano-Santoro, H., J. B. Parent, L. Grinna, A. Horwitz, T. Parsons, G. Theofan, P. Elsbach, J. Weiss, and P. J. Conlon. 1992. Highaffinity binding of the bactericidal/permeability-increasing protein and a recombinant amino-terminal fragment to the lipid A region of lipopolysaccharide. Infect. Immun. 60:4754-4761. https://doi .org/10.1128/IAI.60.11.4754-4761.1992.

Gerber, S. A., J. Rush, O. Stemman, M. W. Kirschner, and S. P. Gygi. 2003. Absolute quantification of proteins and phosphoproteins from cell lysates by tandem MS. Proc. Natl. Acad. Sci. USA 100:6940-6945. https://doi.org/10.1073/pnas.0832254100.

Gillet, L. C., P. Navarro, S. Tate, H. L. Rost, N. Selevsek, L. Reiter, and R. Aebersold. 2012. Targeted data extraction of the MS/MS spectra generated by data-independent acquisition: A new concept for consistent and accurate proteome analysis. Molec. Cell. Proteom. 11:O111.016717.

Goossens, K., A. Van Soom, A. Van Zeveren, H. Favoreel, and L. J. Peelman. 2009. Quantification of Fibronectin 1 (FN1) splice variants, including two novel ones, and analysis of integrins as candidate FN1 receptors in bovine preimplantation embryos. BMC Dev. Biol. 9:1-16. https://doi.org/10.1186/1471-213X-9-1.

Harding, F., and E. Garry. 2005. Collaborative evaluation of a fluorometric method for measuring alkaline phosphatase activity in cow's, sheep's, and goat's milk. J. Food Prot. 68:1047-1053. https: //doi.org/10.4315/0362-028X-68.5.1047.

Izquierdo-González, J. J., F. Amilruiz, S. Zazzu, R. Sanchezlucas, C. A. Fuentesalmagro, and M. J. Rodriguezortega. 2019. Proteomic analysis of goat milk kefir: Profiling the fermentation-time dependent protein digestion and identification of potential peptides with biological activity. Food Chem. 295:456-465. https://doi.org/10 .1016/j.foodchem.2019.05.178.

Jerhammar, F., R. Ceder, S. Garvin, R. Grénman, R. C. Grafström, and K. Roberg. 2010. Fibronectin 1 is a potential biomarker for 
radioresistance in head and neck squamous cell carcinoma. Cancer Biol. Ther. 10:1244-1251. https://doi.org/10.4161/cbt.10.12 .13432

Kanehisa, M. 2019. Toward understanding the origin and evolution of cellular organisms. Protein Sci. 28:1947-1951.

Kanehisa, M., M. Furumichi, Y. Sato, M. Ishiguro-Watanabe, and M. Tanabe. 2021. KEGG: Integrating viruses and cellular organisms. Nucleic Acids Res. 49:D545-D551.

Kanehisa, M., and S. Goto. 2000. KEGG: Kyoto Encyclopedia of Genes and Genomes. Nucleic Acids Res. 28:27-30.

Kourtzelis, I., and S. Rafail. 2016. The dual role of complement in cancer and its implication in anti-tumor therapy. Ann. Transl. Med. 4:265. https://doi.org/10.21037/atm.2016.06.26.

Lakram, N., I. Mercha, E. H. El Maadoudi, R. Kabbour, A. Douaik, A. El Housni, and M. Naciri. 2019. Incorporating detoxified $A r$ gania spinosa press cake into the diet of Alpine goats affects the antioxidant activity and levels of polyphenol compounds in their milk. Int. J. Environ. Stud. 76:815-826. https://doi.org/10.1080/ 00207233.2019.1622941.

Lee, D. H., Y. Y. Jung, M. H. Park, M. R. Jo, S. B. Han, D. Y. Yoon, Y. S. Roh, and J. T. Hong. 2019. Peroxiredoxin 6 confers protection against non-alcoholic fatty liver disease through maintaining mitochondrial function. Antioxid. Redox Signal. 31:387-402. https: //doi.org/10.1089/ars.2018.7544.

Leketa, K., E. F. Donkin, A. Hassen, and A. M. Akanmu. 2019. Effect of Leucaena leucocephala, as a protein source in a total mixed ration, on milk yield and composition of Saanen milk goats. S. Afr. J. Anim. Sci. 49:301-309. https://doi.org/10.4314/sajas.v49i2.10.

Li, S., L. Li, Q. K. Zeng, J. X. Liu, Y. X. Yang, and D. X. Ren. 2018. Quantitative differences in whey proteins among Murrah, Nili-Ravi and Mediterranean buffaloes using a TMT proteomic approach. Food Chem. 269:228-235. https://doi.org/10.1016/j foodchem.2018.06.122.

Lin, L., J. X. Zheng, Q. Yu, W. D. Chen, J. C. Xing, C. X. Chen, and R. J. Tian. 2018. High throughput and accurate serum proteome profiling by integrated sample preparation technology and singlerun data independent mass spectrometry analysis. J. Proteomics 174:9-16. https://doi.org/10.1016/j.jprot.2017.12.014.

Liu, Y., J. Chen, A. Sethi, Q. K. Li, L. Chen, B. Collins, L. C. J. Gillet, B. Wollscheid, H. Zhang, and R. Aebersold. 2014. Glycoproteomic analysis of prostate cancer tissues by swath mass spectrometry discovers n-acylethanolamine acid amidase and protein tyrosine kinase 7 as signatures for tumor aggressiveness. Mol. Cell. Proteomics 13:1753-1768. https://doi.org/10.1074/mcp.M114.038273.

Liu, Y., W. J. Zhang, B. S. Han, L. N. Zhang, and P. Zhou. 2020. Changes in bioactive milk serum proteins during milk powder processing. Food Chem. 314:126177. https://doi.org/10.1016/j foodchem.2020.126177.

Lu, N.-F., L. Jiang, B. Zhu, D.-G. Yang, R.-Q. Zheng, J. Shao, and X.-M. Xi. 2020. Elevated plasma histone H4 level predicts increased risk of mortality in patients with sepsis. Ann. Palliat. Med. 9:1084-1091. https://doi.org/10.21037/apm-20-1011.

Luo, Z., H. Lei, Y. Sun, X. Liu, and D. Su. 2015. Orosomucoid, an acute response protein with multiple modulating activities. J. Physiol. Biochem. 71:329-340. https://doi.org/10.1007/s13105 -015-0389-9.

Ma, S., X. Zhang, L. Zheng, Z. Li, X. Zhao, W. Lai, H. Shen, J. Lv, G. Yang, Q. Wang, and J. Ji. 2016. Peroxiredoxin 6 is a crucial factor in the initial step of mitochondrial clearance and is upstream of the pink1-parkin pathway. Antioxid. Redox Signal. 24:486-501. https://doi.org/10.1089/ars.2015.6336.

Marayati, B. F., J. F. Tucker, D. A. De La Cerda, T. C. Hou, R. Chen, T. Sugiyama, J. B. Pease, and K. Zhang. 2020. The catalytic-dependent and -independent roles of Lsd1 and Lsd2 lysine demethylases in heterochromatin formation in Schizosaccharomyces pombe. Cells 9:955. https://doi.org/10.3390/cells9040955.

Meyer-Hoffert, U. 2009. Neutrophil-derived serine proteases modulate innate immune responses. Front. Biosci. (Landmark Ed) 14:3409. https://doi.org/10.2741/3462.
Park, M. H., M. Jo, Y. R. Kim, C. Lee, and J. T. Hong. 2016. Roles of peroxiredoxins in cancer, neurodegenerative diseases and inflammatory diseases. Pharmacol. Ther. 163:1-23. https://doi.org/10 .1016/j.pharmthera.2016.03.018.

Pastor-Flores, D., D. Talwar, B. Pedre, and T. P. Dick. 2020. Realtime monitoring of peroxiredoxin oligomerization dynamics in living cells. Proc. Natl. Acad. Sci. USA 117:16313-16323. https://doi .org/10.1073/pnas.1915275117.

Rahmatalla, S. A., D. Arends, A. S. Ahmed, M. Reissmann, and G. A. Brockmann. 2020. Whey protein polymorphisms in Sudanese goat breeds. Trop. Anim. Health Prod. 52:1211-1222. https://doi.org/ 10.1007/s11250-019-02119-2.

Rankin, S. A., A. Christiansen, W. Lee, D. S. Banavara, and A. LopezHernandez. 2010. Invited review: The application of alkaline phosphatase assays for the validation of milk product pasteurization. J. Dairy Sci. 93:5538-5551. https://doi.org/10.3168/jds.2010-3400.

Reiter, L., O. Rinner, P. Picotti, R. Hüttenhain, M. Beck, M. Y. Brusniak, M. O. Hengartner, and R. Aebersold. 2011. Mprophet: Automated data processing and statistical validation for large-scale SRM experiments. Nat. Methods 8:430-435.

Samavati, L., and B. D. Uhal. 2020. ACE2, much more than just a receptor for SARS-COV-2. Front. Cell. Infect. Microbiol. 10:317. https://doi.org/10.3389/fcimb.2020.00317.

Sato, S., C. St-Pierre, P. Bhaumik, and J. Nieminen . 2009. Galectins in innate immunity: Dual functions of host soluble beta-galactoside-binding lectins as damage-associated molecular patterns (DAMPs) and as receptors for pathogen-associated molecular patterns (PAMPs). Immunol. Rev. 230:172-187. https://doi.org/10 .1111/j.1600-065X.2009.00790.x.

Scumaci, D., F. Trimboli, L. Dell'Aquila, A. Concolino, G. Pappaianni, L. Tammè, G. Vignola, A. Luciani, D. Morelli, G. Cuda, A. Boari, and D. Britti . 2015. Proteomics-Driven analysis of ovine whey colostrum. PLoS One 10:e0117433. https://doi.org/10.1371/ journal.pone.0117433.

Shakeel-ur-Rehman, C. M. Fleming, N. Y. Farkye, and P. F. Fox. 2003. Indigenous phosphatases in milk. Advanced Dairy Chemistry-1 Proteins. 1:523-543.

South, A. M., D. I. Diz, and M. C. Chappell. 2020. COVID-19, ACE2, and the cardiovascular consequences. Am. J. Physiol. Heart Circ. Physiol. 318:H1084-H1090. https://doi.org/10.1152/ajpheart .00217 .2020 .

Su, Z., J. Gao, Q. Xie, Y. Wang, and Y. Li. 2020. Possible role of $\beta$-galactosidase in rheumatoid arthritis. Mod. Rheumatol. 30:671680. https://doi.org/10.1080/14397595.2019.1640175.

Sun, Y., C. Wang, X. Sun, and M. Guo. 2019. Comparative proteomics of whey and milk fat globule membrane proteins of Guanzhong goat and Holstein cow mature milk. J. Food Sci. 84:244-253. https: //doi.org/10.1111/1750-3841.14428.

Sun, Y., C. Wang, X. Sun, and M. Guo. 2020. Proteomic analysis of whey proteins in the colostrum and mature milk of Xinong Saanen goats. J. Dairy Sci. 103:1164-1174. https://doi.org/10.3168/ jds.2019-17159.

Sundar, I. K., S. Chung, J. W. Hwang, G. Arunachalam, S. Cook, H. Yao, W. Mazur, V. L. Kinnula, A. B. Fisher, and I. Rahman. 2010. Peroxiredoxin 6 differentially regulates acute and chronic cigarette smoke-mediated lung inflammatory response and injury. Exp. Lung Res. 36:451-462. https://doi.org/10.3109/01902141003754128.

Tanaka, H., M. Meisler, and K. Suzuki. 1975. Activity of human hepatic $\beta$-galactosidase toward natural glycosphingolipid substrates. Biochim. Biophys. Acta 398:452-463. https://doi.org/10.1016/ 0005-2760(75)90196-4.

Theprungsirikul, J., J. T. Thaden, R. M. Wierzbicki, A. S. Burns, S. Skopelja-Gardner, V. G. Fowler Jr., K. L. Winthrop, I. W. Martin, and W. F. C. Rigby. 2020. Low-avidity autoantibodies against bactericidal/permeability increasing protein occur in gram-negative and gram-positive bacteremia. Infect. Immun. 88:e00444-20. https: //doi.org/10.1128/IAI.00444-20.

Wang, Z., X. Ren, B. Gao, X. Yu, X. Zhang, J. Zhang, and P. Liu. 2017. Comparison of carbohydrate metabolism key enzymes in dif- 
ferent generations of growth-selected Portunus trituberculatus families. Aquaculture 477:6-14. https://doi.org/10.1016/j.aquaculture 2017.04.026

Wielgat, P., U. Walczuk, S. Szajda, M. Bień, L. Zimnoch, Z. Mariak, and K. J. J. N.-O. Zwierz. 2006. Activity of lysosomal exoglycosidases in human gliomas. J. Neurooncol. 80:243-249. https://doi .org/10.1007/s11060-006-9188-z.

Yu, Y., Z.-X. Lin, H.-W. Li, H.-Q. Luo, D.-H. Yang, H.-C. Zhou, D.-X. Jiang, D.-C. Zhan, L. Yang, X.-Y. Liang, Z.-H. Yu, and Z.-H. Chen. 2020. Circulating tumor cells and Fibronectin 1 in the prognosis of nasopharyngeal carcinoma. Technol. Cancer Res. Treat. 19:1533033820909911. https://doi.org/10.1177/ 1533033820909911.

Zamolodchikova, T. S., S. M. Tolpygo, and E. V. Svirshchevskaya. 2020. Cathepsin G - not only inflammation: The immune protease can regulate normal physiological processes. Front. Immunol. 11:411. https://doi.org/10.3389/fimmu.2020.00411.
Zeida, A., M. Trujillo, G. Ferrersueta, A. Denicola, D. A. Estrin, and R. Radi. 2019. Catalysis of peroxide reduction by fast reacting protein thiols. Chem. Rev. 119:10829-10855. https://doi.org/10.1021/ acs.chemrev.9b00371.

Zhang, B., Y. Wang, and Y. Su. 2009. Peroxiredoxins, a novel target in cancer radiotherapy. Cancer Lett. 286:154-160. https://doi.org/ 10.1016/j.canlet.2009.04.043.

Zhao, Z. 2021. Table S1, Mendeley Data, V1. https://doi.org/10 $.17632 /$ rz3yzznv6s.1.

\section{ORCIDS}

Cuina Wang @ () https://orcid.org/0000-0002-7528-2458 